\title{
Photodetectors for weak-signal detection fabricated from ZnO:(Li,N) films
}

G. H. He ${ }^{\mathrm{a}, \mathrm{b}}$, H. Zhou ${ }^{\mathrm{c}}$, H. Shen ${ }^{\mathrm{a}}$, Y. J. Lu ${ }^{\mathrm{d}}$, H. Q. Wang ${ }^{\mathrm{c}}$, J. C. Zheng ${ }^{\mathrm{c}}$, B. H. Li ${ }^{\mathrm{a}}$, C. X. Shan $^{\mathrm{a}, \mathrm{d}, *}$, D. Z. Shen ${ }^{\mathrm{a}}$

${ }^{\text {a }}$ State Key Laboratory of Luminescence and Applications, Changchun Institute of Optics, Fine Mechanics and Physics, Chinese Academy of Sciences Changchun 130033, China.

${ }^{\mathrm{b}}$ University of Chinese Academy of Sciences, Beijing 100049, China.

c Key Laboratory of Semiconductors and Applications of Fujian Province, Collaborative Innovation Center for Optoelectronic Semiconductors and Efficient Devices, Department of Physics, Xiamen University, Xiamen 361005, China.

${ }^{\mathrm{d}}$ Henan Key Laboratory of Diamond Optoelectronic Materials and Devices, School of Physics and Engineering, Zhengzhou University, Zhengzhou 450001, China.

E-mail: $\underline{\text { shancx@ @iomp.ac.cn }}$

Abstract: $\mathrm{ZnO}$ films with carrier concentration as low as $5.0 \times 10^{13} \mathrm{~cm}^{-3}$ have been prepared via a lithium and nitrogen codoping method, and ultraviolet photodetectors have been fabricated from the films. The photodetectors can be used to detect weak signals with power density as low as $20 \mathrm{nw} / \mathrm{cm}^{2}$, and the detectivity and noise equivalent power of the photodetector can reach $3.60 \times 10^{15} \mathrm{cmHz}^{1 / 2} / \mathrm{W}$ and $6.67 \times 10^{-18}$ $\mathrm{W}^{-1}$, respectively, both of which are amongst the best values ever reported for $\mathrm{ZnO}$ based photodetectors. The high-performance of the photodetector can be attributed to the relatively low carrier concentration of the $\mathrm{ZnO}:(\mathrm{Li}, \mathrm{N})$ films.

Key words: Photodetector; $\mathrm{ZnO}$; Detectivity; Noise equivalent power.

*Author to whom correspondence should be addressed, Email: shancx@ ciomp.ac.cn. 


\section{Introduction}

As a type of electronic devices for sensing light, photodetectors have a variety of potential applications in both civil and military fields such as sensors, radiation calibration and monitoring, astronomical studies, optical communication, missile launch detection, and so on [1-6]. Because of the above potential applications, the development of photodetectors is very important and urgent. $\mathrm{ZnO}$ is a wide band gap (3.37 $\mathrm{eV}$ at room temperature) semiconductor, which makes it suitable for applications in short-wavelength ultraviolet (UV) optoelectronic devices, such as photodetectors, light-emitting devices, lasers, and so on [7-12]. So far various typed $\mathrm{ZnO}$ photodetectors, such as Schottky photodiodes, metal-semiconductor-metal (MSM) photodetectors [13-15] and $p-n$ junction photodiodes [16,17] have been demonstrated. However, the performance of the photodetector devices is far behind expectation. Especially $\mathrm{ZnO}$ photodetectors that can be employed to detect weak signals are still eagerly wanted, which has been one of the largest obstacles for the future applications of $\mathrm{ZnO}$ based UV photodetectors.

In this paper, high-resistance $\mathrm{ZnO}$ films have been prepared by using lithium and nitrogen codoping method, and the carrier concentration of the films is $5 \times 10^{13} \mathrm{~cm}^{-3}$, which is over four orders of magnitude smaller than that of undoped $\mathrm{ZnO}$ films $\left(5.7 \times 10^{17} \mathrm{~cm}^{-3}\right)$. The relatively low carrier concentration is favorable for the realization of photodetectors that can be employed for weak signal detection. Photodetectors fabricated from the films show capability to detect weak signals as low as $20 \mathrm{nw} / \mathrm{cm}^{2}$, and the detectivity and noise equivalent power (NEP) of the photodetector can reach $3.60 \times 10^{15} \mathrm{cmHz}^{1 / 2} / \mathrm{W}$ and $6.67 \times 10^{-18} \mathrm{~W}^{-1}$, respectively, both of which are amongst the best values ever reported for $\mathrm{ZnO}$ photodetectors. 


\section{Experiments}

The Li,N codoped $\mathrm{ZnO}(\mathrm{ZnO}:(\mathrm{Li}, \mathrm{N}))$ thin films employed as the active layer of the photodetector were grown on $c$-plane sapphire by plasma assisted molecular beam epitaxy technique. Prior to the growth, the sapphire substrates were treated at $650^{\circ} \mathrm{C}$ for 30 min to clean the surface. Elemental zinc $(6 \mathrm{~N})$ and lithium $(3 \mathrm{~N})$ contained in Knudsen effusion cells were used as $\mathrm{Zn}$ and $\mathrm{Li}$ source. Oxygen $(6 \mathrm{~N})$ cracked via a radio-frequency atom source was used as $\mathrm{O}$ source, nitric oxide (NO) gas $(6 \mathrm{~N})$ cracked via a radio-frequency atom source was used as $\mathrm{N}$ and $\mathrm{O}$ source for the growth of the $\mathrm{ZnO}:(\mathrm{Li}, \mathrm{N})$ films. During the growth progress, the substrate temperature was fixed at $650^{\circ} \mathrm{C}$, and the pressure in the growth chamber at $2 \times 10^{-5} \mathrm{mbar}$. To fabricate $\mathrm{ZnO}$ :(Li,N) based photodetectors, a thin Au layer was deposited onto the films by vacuum evaporation method, and interdigital electrodes were configured on the films via a photolithography and wet etching process.

The crystalline properties of the $\mathrm{ZnO}:(\mathrm{Li}, \mathrm{N})$ films were characterized by a Bruker D8 Discover x-ray diffractometer (XRD) with $\mathrm{Cu} K \alpha(\lambda=1.54 \AA)$ as the radiation source. Electrical properties of the films were measured in a Hall measurement system (Lakeshore 7707) under Van der Pauw configuration. The surface morphology of the $\mathrm{ZnO}:(\mathrm{Li}, \mathrm{N})$ films was characterized by a Hitachi $\mathrm{S} 4800$ field-emission scanning electron microscope (SEM). The chemical bonding states in the $\mathrm{ZnO}:(\mathrm{Li}, \mathrm{N})$ films was analyzed in an AXIS Ultra 'DLD' X-ray photoelectron spectrometer (XPS). X-ray absorption near edge structure (XANES) spectra of O K-edge in the ZnO:(Li,N) films were obtained at the Photoemission Spectroscopy station (Beam line 4B9B) of Beijing Synchrotron Radiation Facility. Extended x-ray absorption fine structure (EXAFS) spectra of Zn K-edge in the samples were collected at the X-ray Absorption Fine Structure station (Beam line 14 W1) of Shanghai Synchrotron Radiation Facility 
using the fluorescence mode at room temperature. The acceptor state of the $\mathrm{ZnO}:(\mathrm{Li}, \mathrm{N})$ films has been studied by investigating the local electronic structures of the films using $\mathrm{x}$-ray absorption fine structure (XAFS) based on synchrotron radiation source, and such a technique has been employed to study the local electronic structures of $\mathrm{ZnO}[18,19]$. The current-voltage $(I-V)$ properties of the devices were measured using a semiconductor parameter analyzer (Keithely 2200).

\section{Results and discussion}

Figure 1(a) shows the XRD patterns of the undoped $\mathrm{ZnO}$ and $\mathrm{ZnO}:(\mathrm{Li}, \mathrm{N})$ films, from which one can see that for both cases, besides the diffraction from the sapphire substrate, a strong peak can be observed, which can be indexed to the diffraction from (002) facet of $\mathrm{ZnO}$. The strong (002) diffraction peak indicates that both the $\mathrm{ZnO}:(\mathrm{Li}, \mathrm{N})$ films and undoped $\mathrm{ZnO}$ films are crystallized in wurtzite structure. The plan-view SEM images of the $\mathrm{ZnO}:(\mathrm{Li}, \mathrm{N})$ films are displayed in Figures 1(b). One can see that the $\mathrm{ZnO}:(\mathrm{Li}, \mathrm{N})$ films have a smooth surface.

Under dark conditions, the electrical conductivity of a semiconductor can be expressed by the following formula:

$$
\sigma_{0}=q\left(n_{0} \mu_{n}+p_{0} \mu_{p}\right)
$$

In which $q$ is the electron charge; $n_{0}$ and $p_{0}$ are the equilibrium carrier concentration; $\mu_{n}, \mu_{p}$ is the mobility of the electrons and holes, respectively. When the semiconductor is exposed to illumination, $\Delta n$ and $\Delta p$ are the number of the photon-generated carriers. The $\sigma_{0}$ become $\sigma$

$$
\sigma=q\left(n \mu_{n}+p \mu_{p}\right)
$$

$n=n_{0}+\Delta n$ and $p=p_{0}+\Delta p$. We can get the photoconduction $\Delta \sigma=q\left(\Delta n \mu_{n}+\Delta p \mu_{p}\right)$. The relative value is 


$$
\Delta \sigma / \sigma_{0}=\left(\Delta n \mu_{n}+\Delta p \mu_{p}\right) /\left(n_{0} \mu_{n}+p_{0} \mu_{p}\right)
$$

From the above formula, one can see that to get high photoconductivity, the $n_{0}$ and $p_{0}$ must be as small as possible. Table I shows the electrical properties of the undoped and $\mathrm{ZnO}:(\mathrm{Li}, \mathrm{N})$ films. The Hall mobility of the $\mathrm{ZnO}:(\mathrm{Li}, \mathrm{N})$ is smaller than the undoped $\mathrm{ZnO}$ film, but the carrier concentration in the doped films is as low as $5.0 \times 10^{13} \mathrm{~cm}^{-3}$, which is about four order of magnitude lower than in the undoped $\mathrm{ZnO}$ films $\left(5.7 \times 10^{17} \mathrm{~cm}^{-3}\right)$. The reason for the decreased carrier concentration in the $\mathrm{ZnO}:(\mathrm{Li}, \mathrm{N})$ films will be depicted below.

Table I. Hall data of the undoped $\mathrm{ZnO}$ and $\mathrm{ZnO}:(\mathrm{Li}, \mathrm{N})$ films.

\begin{tabular}{c|cccc}
\hline Sample & Conductivity & $\begin{array}{c}\text { Hall } \\
\text { mobility }\end{array}$ & $\begin{array}{c}\text { Carrier } \\
\text { concentration }\end{array}$ & $\begin{array}{c}\text { Resistivity } \\
(\Omega \mathrm{cm})\end{array}$ \\
\hline $\mathrm{ZnO}$ & $n$ & 20.6 & $5.7 \times 10^{17}$ & $5.29 \times 10^{-1}$ \\
$\mathrm{ZnO}:(\mathrm{Li}, \mathrm{N})$ & $n$ & 3.5 & $5.0 \times 10^{13}$ & $9.81 \times 10^{3}$ \\
\hline
\end{tabular}

Figure 2 shows the XPS spectrum of the $\mathrm{ZnO}(\mathrm{Li}, \mathrm{N})$ film, and the composition of the $\mathrm{Li}$ and $\mathrm{N}$ in the $\mathrm{ZnO}:(\mathrm{Li}, \mathrm{N})$ films determined by XPS is around $3.46 \%$ and $0.49 \%$, respectively. In Figure 2(a), a $\mathrm{Li} 1 \mathrm{~s}$ peak is evidenced at $55.3 \mathrm{eV}$, which is close to the binding energy of $\mathrm{Li}$ in $\mathrm{Li}-\mathrm{N}$ bonds $(55.0 \mathrm{eV})$ and $\mathrm{Li}-\mathrm{O}$ bonds $(55.6 \mathrm{eV})$ [20,21]. No signal from $\mathrm{Li}_{\mathrm{i}}(52.9 \mathrm{eV})$ can be found, revealing that the incorporated Li may occupy $\mathrm{Zn}$ sites to form the acceptors $\mathrm{Li}_{\mathrm{Zn}}$ bonding with $\mathrm{N}$ and/or $\mathrm{O}$, while the $\mathrm{Li}_{\mathrm{i}}$ that is frequently observed in $\mathrm{Li}$ doped $\mathrm{ZnO}$ has not been observed in our case. The N1s spectrum shown in Figure 2(b) is located at $398.8 \mathrm{eV}$, which is close to the binding energy of Li-N bonds. One can deduce from the above data that $\mathrm{Li}-\mathrm{N}$ bonds form in the $\mathrm{ZnO}:(\mathrm{Li}, \mathrm{N})$ films. Thus, it is rational to speculate from the XPS data that the acceptor formed in $\mathrm{ZnO}:(\mathrm{Li}, \mathrm{N})$ film may be the $\mathrm{Li}-\mathrm{N}$ complex containing $\mathrm{Li}_{\mathrm{Zn}}$ and 
$\mathrm{N}_{\mathrm{O}}$.

In order to further prove the above speculation, the O K-edge XANES absorption spectra of the $\mathrm{ZnO}:(\mathrm{Li}, \mathrm{N}), \mathrm{ZnO}: \mathrm{N}, \mathrm{ZnO}: \mathrm{Li}$, and $\mathrm{ZnO}$ films have been measured, as shown in Figure 3(a). There are three main bulge areas marked A, B, C in the spectra. The most distinctive features from the four samples with different doping status appear in the $\mathrm{C}$ area, which is located at approximately from $539 \mathrm{eV}$ to $550 \mathrm{eV}$, and is mainly attributed to $\mathrm{O} 2 p$ hybridized with $\mathrm{Zn} 4 p$ states in the films [22]. The $\mathrm{C}$ area is composed of two small bulges, originated from $\mathrm{O} p_{\mathrm{z}}$ and $p_{\mathrm{x}}\left(p_{\mathrm{y}}\right)$ orbits, thus it can reflect the change of $\mathrm{O} p$ orbit directly. As illustrated in Figure 3(a), the intensity of C area in the $\mathrm{ZnO}: \mathrm{N}$ film is larger than that in undoped $\mathrm{ZnO}$ films. Such a phenomenon may be caused by the fact that some $\mathrm{O}$ positions have been occupied by $\mathrm{N}$, which will lead to the decrease of electron number, thus the increased absorption intensity of the $\mathrm{O} p$ orbit has been resulted for the nitrogen doped $\mathrm{ZnO}$ films compared with the undoped ones. On the other hand, as Li doping does not influence the $\mathrm{O} p$ orbit, the $\mathrm{C}$ area in $\mathrm{ZnO}: \mathrm{Li}$ shows no obvious change from that in the undoped $\mathrm{ZnO}$ films. The intensity of $\mathrm{C}$ area in the $\mathrm{ZnO}:(\mathrm{Li}, \mathrm{N})$ lies between that of $\mathrm{ZnO}: \mathrm{N}$ and $\mathrm{ZnO}$ films, which may be due to the fact that the Li bonding with $\mathrm{N}$ will partially offset the impact of $\mathrm{O} p$ orbit caused by the $\mathrm{N}$ occupying $\mathrm{O}$ site. The above results are consistent with the speculation shown in the XPS data that $\mathrm{N}$ has been bonded with Li in the $\mathrm{ZnO}:(\mathrm{Li}, \mathrm{N})$ films.

The Zn K-edge EXAFS spectra of the samples were analyzed by Athena V0.8.056, Artemis V0.8.012 with the IFEFFIT package version 1.2.11 [23-25]. Both the experimental results and the fitting curves are displayed in R-space and provided in Figure 3(b) and the detailed analysis procedure can be found elsewhere [26]. In the simulation of the $\mathrm{ZnO}:(\mathrm{Li}, \mathrm{N})$ film, $\mathrm{Li}$ and $\mathrm{N}$ are assumed to substitute for the $\mathrm{Zn}$ and 
O sites, respectively. The dashed lines in Figure 3(b) show the Fourier transformed experimental EXAFS data of the undoped $\mathrm{ZnO}$ films (thin dashed line) and $\mathrm{ZnO}$ :(Li,N) films (thick dashed line). The solid lines are Artemis fitting data, well fitted to the experimental data. The first shell of the radial distribution function indicates the position of the $\mathrm{Zn}-\mathrm{O}$ bond distance, and the second shell peak denotes a combination of $\mathrm{Zn}-\mathrm{Zn}$ bond distances. The best fitting results of the bond length are presented in Figure 3(b) and the bond length data obtained via the fitting are summarized in Table II. The undoped $\mathrm{ZnO}$ film has $\mathrm{Zn}-\mathrm{O}$ and $\mathrm{Zn}-\mathrm{Zn}$ bond length of $1.972 \AA$ and $3.190 \AA$, respectively. The bond length of $\mathrm{Zn}-\mathrm{O}$ in the $\mathrm{ZnO}:(\mathrm{Li}, \mathrm{N})$ film is shorter than that in the undoped $\mathrm{ZnO}$ film. One may speculate that the length of $\mathrm{Zn}-\mathrm{Zn}$ bonds will be increased if $\left(\mathrm{N}_{2}\right)_{\mathrm{O}}$ or $\mathrm{Li}_{\mathrm{i}}$ is dominant because both of them will occupy larger space than a single $\mathrm{O}$ atom, and the $\mathrm{Zn}$ atoms will then be pushed away from their original sites. The fact that the $\mathrm{Zn}-\mathrm{Zn}$ bonding length has been decreased, instead indicates that $\mathrm{N}$ and $\mathrm{Li}$ mainly exist in the forms of $\mathrm{N}_{\mathrm{O}}$ and $\mathrm{Li}_{\mathrm{Zn}}$. These findings further confirm the formation of Li-N complex acceptors have formed in the $\mathrm{ZnO}:(\mathrm{Li}, \mathrm{N})$ films. The low carrier concentration may be caused by the compensation of the $\mathrm{N}_{\mathrm{O}}$ and $\mathrm{Li}_{\mathrm{Zn}}$ acceptors to the residual donors in the $\mathrm{ZnO}$ films, which is favorable for weak signal detection if a photodetector can be fabricated from the $\mathrm{ZnO}$ films.

Table II. Bond lengths of the $\mathrm{ZnO}:(\mathrm{Li}, \mathrm{N})$ and undoped $\mathrm{ZnO}$ films from $\mathrm{Zn} \mathrm{K}$-edge EXAFS analysis.

\begin{tabular}{ccc}
\hline Sample & Zn-O bond length $(\AA)$ & Zn-Zn bond length $(\AA)$ \\
\hline ZnO & 1.972 & 3.19 \\
ZnO: $(\mathrm{Li}, \mathrm{N})$ & 1.943 & 3.153 \\
\hline
\end{tabular}


The schematic illustration of the photodetector fabricated from the $\mathrm{ZnO}:(\mathrm{Li}, \mathrm{N})$ films is shown in Figure 4(a). The interdigital Au electrodes are consisted of 12 fingers for each electrode, the fingers are $5 \mu \mathrm{m}$ in width, $500 \mu \mathrm{m}$ in length, and the spacing between the fingers is $5 \mu \mathrm{m}$. The $I-V$ curves of the device measured in dark and illumination conditions are shown in Figure 4(b). The dark current of the device is as low as $145 \mathrm{pA}$ at $10 \mathrm{~V}$ bias, while under the illumination of the $360 \mathrm{~nm}$ line of a Xenon lamp with the power density of $510 \mathrm{nW} / \mathrm{cm}^{2}$, the current is $108 \mathrm{nA}$ at $10 \mathrm{~V}$ bias, which means that under illumination many carriers have been generated. The above data reveals that the device can be employed to detect UV photons.

Figure 5 shows the response spectrum of the photodetector, and the absorption spectrum of the $\mathrm{ZnO}:(\mathrm{Li}, \mathrm{N})$ films has also been displayed. From the absorption spectrum, a strong peak at around $370 \mathrm{~nm}$ is visible, which can be attributed to the excitonic absorption of $\mathrm{ZnO}$, and the absorption in the $\mathrm{UV}$ region is strong, while that in the visible region is weak, which is favorable for UV photodetector fabricated from the films. The response spectrum of the device shows a broad peak centered at around $370 \mathrm{~nm}$. The responsivity of the photodetector increases with the bias, and it can reach $287 \mathrm{~A} / \mathrm{W}$ when the bias is $20 \mathrm{~V}$.

Figure 6 (a) shows the relationship between the responsivity and the power density of the illumination source when the bias voltage is $20 \mathrm{~V}$, it is obvious from the figure that when the power density of the illumination source is $2 \mathrm{~mW} / \mathrm{cm}^{2}$, the responsivity of the photodetector at $20 \mathrm{~V}$ is $116 \mathrm{~A} / \mathrm{W}$. The photodetector can still work when the power density of the illumination source is as low as $50 \mathrm{nW} / \mathrm{cm}^{2}$, and the responsivity of the photodetector can reach $216 \mathrm{~A} / \mathrm{W}$ at $20 \mathrm{~V}$ for the detection of such weak signals.

Detectivity $\left(D^{*}\right)$ and noise equivalent power $(N E P)$ are two important parameters 
that determine the performance of detecting weak signals for a photodetector. $D^{*}$ and NEP of a photodetector can be expressed by the following formula [27]:

$$
\begin{aligned}
& D^{*}=R_{\lambda}\left(R_{0} / 4 K T\right)^{1 / 2} \\
& N E P=A^{1 / 2} B^{1 / 2} D^{*}
\end{aligned}
$$

Here $R_{\lambda}$ is the responsivity of the photodetector; $R_{0}$ is the dark impedance; $A$ is the active area of the photodetector $\left(5.75 \times 10^{-4} \mathrm{~cm}^{2}\right.$ in our case $) ; B$ is the bandwidth. Base on these two equations, the detectivity and NEP can be acquired. We note that the detectivity and NEP of the photodetector is strongly related to the power density of the illumination source, as shown in Figure 6(b). The detectivity increases firstly and then decreases with the power density of the illumination source is increased. The detectivity and $N E P$ of the photodetector at $20 \mathrm{~V}$ can reach $3.60 \times 10^{15} \mathrm{cmHz}^{1 / 2} / \mathrm{W}$ and $6.67 \times 10^{-18} \mathrm{~W}^{-1}$, respectively, when the power density of the illumination source is reduced to $20 \mathrm{nW} / \mathrm{cm}^{2}$, both of which are amongst the best values ever reported for $\mathrm{ZnO}$ based photodetectors, as illustrated in Table III.

Table III. Comparison of the $D^{*}$ and $N E P$ of the photodetectors fabricated from the $\mathrm{ZnO}(\mathrm{Li}: \mathrm{N})$ films with the reported values.

\begin{tabular}{ccccc}
\hline ZnO structure & $\mathrm{D}^{*}(\mathrm{cmHz} / \mathrm{W})$ & $\mathrm{NEP}\left(\mathrm{W}^{-1}\right)$ & Voltage $(\mathrm{V})$ & Reference \\
\hline Thin film & $1.19 \times 10^{10}$ & $2.65 \times 10^{-12}$ & 5 & {$[28]$} \\
Nanowall & $3.38 \times 10^{9}$ & $1.87 \times 10^{-10}$ & 2 & {$[29]$} \\
Nanorod & $1.43 \times 10^{15}$ & $2.27 \times 10^{-14}$ & 5 & {$[30]$} \\
Nanowire & $2.13 \times 10^{9}$ & $5.83 \times 10^{-13}$ & 1.5 & {$[31]$} \\
Nanoparticle & $3.43 \times 10^{15}$ & $\mathrm{NA}$ & 9 & {$[32]$} \\
Thin film & $3.60 \times 10^{15}$ & $6.67 \times 10^{-18}$ & 20 & This work \\
\hline
\end{tabular}




\section{Conclusions}

In conclusion, photodetectors that are capable of detecting weak signals have been developed from $\mathrm{ZnO}:(\mathrm{Li}, \mathrm{N})$ films, and when the power density of the illumination source is as low as $20 \mathrm{nW}$, the detectivity and $N E P$ of the photodetector can reach $3.60 \times 10^{15} \mathrm{cmHz}^{1 / 2} / \mathrm{W}$ and $6.67 \times 10^{-18} \mathrm{~W}^{-1}$, both of which are amongst the best values ever reported for $\mathrm{ZnO}$ based photodetectors. The high-performance of the photodetector can be attributed to the relatively low carrier concentration of the $\mathrm{ZnO}:(\mathrm{Li}, \mathrm{N})$ films caused by the compensation of the incorporated acceptors to the residual donors. The results reported in this paper may provide a route to $\mathrm{ZnO}$ photodetectors that is capable of detecting weak signals.

\section{Acknowledgement:}

The authors would like to express our sincere appreciation to the kind help from Shanghai Synchrotron Radiation Facility (SSRF) and Beijing Synchrotron Radiation Facility (BSRF). This work is financially supported by the National Science Foundation for Distinguished Young Scholars of China (61425021), the Natural Science Foundation of China (11374296, U1604263, and 61604132), and the National Program for Support of Top-notch Young Professionals. 


\section{Reference:}

${ }^{[1]}$ R. Baraki, N. Novak, T. Frömling, T. Granzow and J. Rödel, Bulk ZnO as piezotronic pressure sensor, Appl. Phys. Lett. 105 (2014) 111604.

${ }^{[2]}$ D. Gedamu, I. Paulowicz, S. Kaps, O. Lupan, S. Wille, G. Haidarschin, Y. K. Mishra, and R. Adelung, Rapid Fabrication Technique for Interpenetrated $\mathrm{ZnO}$ Nanotetrapod Networks for Fast UV Sensors, Adv. Mater. 26 (2014) 1541.

${ }^{[3]}$ L. Peng, L. Hu and X. Fang, Low-Dimensional Nanostructure Ultraviolet Photodetectors, Adv. Mater. 25 (2013) 5321.

${ }^{\left[{ }^{4}\right]}$ J. Wang, X. Li, Y. Xia, S. Komarneni, H. Chen, J. Xu, L. Xiang and D. Xie, Hierarchical $\mathrm{ZnO}$ nanosheet-nanorod architectures for fabrication of poly(3-hexylthiophene)/ZnO hybrid $\mathrm{NO}_{2}$ sensor, ACS Appl. Mater. Interfaces 8 (2016) 8600.

${ }^{[5]}$ T. Tesfamichael, C. Cetin, C. Piloto, M. Arita, J. Bell, The effect of pressure and W-doping on the properties of $\mathrm{ZnO}$ thin films for $\mathrm{NO}_{2}$ gas sensing, Appl. Surf. Sci. 357 (2015) 728.

${ }^{[6]}$ S. Park, S. An, H. Ko, C. Jin and C. Lee, Synthesis of Nanograined ZnO Nanowires and Their Enhanced Gas Sensing Properties, ACS Appl. Mat. Interfaces 4 (2012) 3650 .

${ }^{[7]}$ J.N. Pei, D. Y. Jiang, M. Zhao, Q. Duan, R. S. Liu, L. Sun, Z. X. Guo, J. H. Hou, J. M. Qin, B. Z. Li, G. Y. Zhang, Controlled enhancement range of the responsivity in $\mathrm{ZnO}$ ultravioletphotodetectors by Pt nanoparticles, Appl. Surf. Sci. 389 (2016) 1056.

${ }^{[8]}$ H. Zhu, C. X. Shan, B. Yao, B. H. Li, J. Y. Zhang, Z. Z. Zhang, D. X. Zhao, D. Z. Shen, X. W. Fan, Y. M. Lu, and Z. K. Tang, Ultralow-Threshold Laser Realized in Zinc Oxide, Adv. Mater. 21 (2009) 1613.

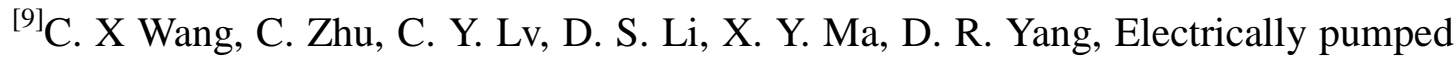
random lasing from hydrothermal ZnO filmsof large grains, Appl. Surf. Sci. 332 (2015) 620.

${ }^{[10]}$ C. Soci, A. Zhang, B. Xiang, S. A. Dayeh, D. P. R. Aplin, J. Park, X. Y. Bao, Y. H. Lo and D. Wang, ZnO Nanowire UV Photodetectors with High Internal Gain, 
Nano Lett. 7 (2007) 1003.

${ }^{[11]}$ Y. Y. Lai, Y. P. Lan and T. Ch Lu, Strong light-matter interaction in ZnO microcavities, Light: Sci. Appl. 2 (2013), e76.

${ }^{[12]}$ Y. H. Lee, D. H. Kim and T. W. Kim, Enhanced current efficiency of organic light-emitting devices due to a broad localized surface plasmonic resonance of $\mathrm{Au}-\mathrm{ZnO}$ nanocomposites, Appl. Surf. Sci. 355 (2015) 359.

${ }^{[13]}$ T. K. Lin, S. J. Chang, Y. K. Su, B. R. Huang, M. Fujita and Y. Horikoshi, ZnO MSM photodetectors with Ru contact electrodes J. Cryst. Growth 281 (2005) 513.

${ }^{[14]}$ S. J. Young, L. W. Ji, S. J. Chang and X. L. Du, ZnO Metal-Semiconductor-Metal Ultraviolet Photodiodes with Au Contacts, J. Electrochem. Soc. 154 (2007) 26.

${ }^{[15]}$ N. N. Jandow, K. Ibrahim and H. A. Hassan, I-V Characteristic for ZnO MSM Photodetector with Pd Contact Electrodes on PPC Plastic, AIP Conf. Proc. 1250 (2010) 424.

${ }^{[16]}$ H. Wang, G. B. Yi, X. H. Zu, P. Qin, M. Tan and H. S. Luo, Photoelectric characteristics of the $p-n$ junction between $\mathrm{ZnO}$ nanorods and polyaniline nanowires and their application as a UV photodetector, Mater. Lett. 162 (2016) 83.

${ }^{[17]}$ H. Shen, C. X. Shan, B. H. Li, B. Xuan and D. Z. Shen, Reliable self-powered highly spectrum-selective ZnO ultraviolet photodetectors Appl. Phys. Lett. 103 (2013) 232112.

${ }^{[18]}$ P. Fons, H. Tampo, A. V. Kolobov, M. Ohkubo, S. Niki, J. Tominaga, R. Carboni, F. Boscherini, S. Friedrich, Direct observation of nitrogen location in molecular beam epitaxy grown nitrogen doped ZnO, Phys. Rev. Lett. 96 (2006) 045504.

${ }^{[19]}$ S. Y. Tsai, M. H. Hon, and Y. M. Lu, Local electronic structure of lithium-doped $\mathrm{ZnO}$ films investigated by X-ray absorption near-edge spectroscopy, J. Phys. Chem. C 115 (2011) 10252.

${ }^{[20]}$ J. Sharma, T. Gora, J. D. Rimstidt and R. Staley, X-ray photoelectron spectra of the alkali azides, Chem. Phys. Lett. 15 (1972) 232.

${ }^{[21]}$ J.S. Mrowiecka, V. Maurice, S. Zanna, L. Klein and P. Marcus, XPS study of Li ion intercalation in $\mathrm{V}_{2} \mathrm{O}_{5}$ thin films prepared by thermal oxidation of vanadium metal, 
Electrochim. Acta. 52 (2007) 5644.

${ }^{[22]}$ H. Zhou, H. Q. Wang, X. X. Liao, Y. Zhang, J. C. Zheng, J. O. Wang, E. Muhemmed, H. J. Qian, K. Ibrahim, X. Chen, H. Zhan and J. Kang, Tailoring of polar and nonpolar $\mathrm{ZnO}$ planes on $\mathrm{MgO}$ (001) substrates through molecular beam epitaxy, Nanoscale Res. Lett. 7 (2012) 184.

${ }^{[23]}$ M. Newville, IFEFFIT: interactive XAFS analysis and FEFF fitting, J. Synchrotron Radiat. 8 (2001) 322.

${ }^{[24]}$ B. Ravel, M. Newville, ATHENA, ARTEMIS, HEPHAESTUS: data analysis for X-ray absorption spectroscopy using IFEFFIT, J. Synchrotron Radiat. 12 (2005) 537.

${ }^{[25]}$ B. Ravel, ATOMS: crystallography for the X-ray absorption spectroscopist, J. Synchrotron Radiat. 8 (2001) 314.

${ }^{[26]}$ H. Zhou, H. Q. Wang, Y. Li, K. Li, J. Y. Kang, J. C. Zheng, Z. Jiang, Y. Y. Huang, L. J. Wu, L. H. Zhang, K. Kisslinger and Y. M. Zhu, Evolution of Wurtzite ZnO Films on Cubic MgO (001) Substrates: A Structural, Optical, and Electronic Investigation of the Misfit Structures, ACS Appl. Mater. Interfaces 6 (2014) 13823.

${ }^{[27]}$ H. Zhu, C. X. Shan, L. K. Wang, J. Zheng, J. Y. Zhang, B. Yao and D. Z. Shen, Metal-Oxide-Semiconductor-Structured MgZnO Ultraviolet Photodetector with High Internal Gain, J. Phys. Chem. C. 114 (2010) 7169.

${ }^{[28]}$ H. Y. Lee, Y. T. Hsu and C. T. Lee, ZnO-based resonant cavity enhanced metal-semiconductor-metal ultraviolet photodetectors, Solid-State Electron. 79 (2013) 223.

${ }^{[29]}$ T. P. Chen, F.Y. Hung, S.P. Chang, S.J. Chang, S.L. Wu and Z.S. Hu, Noise Properties of $\mathrm{ZnO}$ Nanowalls Deposited Using Rapid Thermal Evaporation Technology, IEEE Photon Technol. 25 (2013) 213.

${ }^{[30]}$ C. H. Chen, C. T. Lee, High Detectivity Mechanism of ZnO-Based Nanorod Ultraviolet Photodetectors, IEEE Photon Technol. Lett. 25 (2013) 348.

${ }^{[31]}$ H. B. Yu, E. A. Azhar, T. Belagodu, S. Lim and S. Dey, ZnO nanowire based visible-transparent ultraviolet detectors on polymer substrates J. Appl. Phys. 111 (2012) 102806. 
${ }^{[32]}$ F. Guo, B. Yang, Y. Yuan, Z. Xiao, Q. Dong, Y. Bi and J. Huang, A nanocomposite ultraviolet photodetector based on interfacial trap-controlled charge injection, Nat. Nanotechnol. 7 (2012) 798. 


\section{Figure captions:}

Figure 1. (a) XRD patterns of the undoped $\mathrm{ZnO}$ and $\mathrm{ZnO}:(\mathrm{Li}, \mathrm{N})$ films. (b) Plan-view SEM images of the $\mathrm{ZnO}:(\mathrm{Li}, \mathrm{N})$ films.

Figure 2. XPS spectra of $\mathrm{Li} 1 \mathrm{~s}(\mathrm{a})$ and $\mathrm{N}$ 1s (b) in $\mathrm{ZnO}:(\mathrm{Li}, \mathrm{N})$ films.

Figure 3. (a)O K-edge XANES spectra of the $\mathrm{ZnO}:(\mathrm{Li}, \mathrm{N}), \mathrm{ZnO}: \mathrm{N}, \mathrm{ZnO}: \mathrm{Li}$ and undoped $\mathrm{ZnO}$ films. (b) Fourier transformed $\mathrm{Zn}$ K-edge EXAFS data of the $\mathrm{ZnO}:(\mathrm{Li}, \mathrm{N})$ and undoped $\mathrm{ZnO}$ films.

Figure 4. (a) Schematic diagram of the device. (b) Dark current and photo current of the device under the UV illumination with power density of $510 \mathrm{nW} / \mathrm{cm}^{2}$.

Figure 5. (a) The responsivity and absorption spectrum of the photodetector fabricated from the $\mathrm{ZnO}:(\mathrm{Li}, \mathrm{N})$ films. (b) Dependence of the responsivity of the photodetectors on the bias voltage.

Figure 6. (a) The relationship between the responsivity of the photodetector and the power density of the illumination source. (b) The dependence of the detectivity and $N E P$ of the photodetectors on the power density of the illumination source. 
(a)

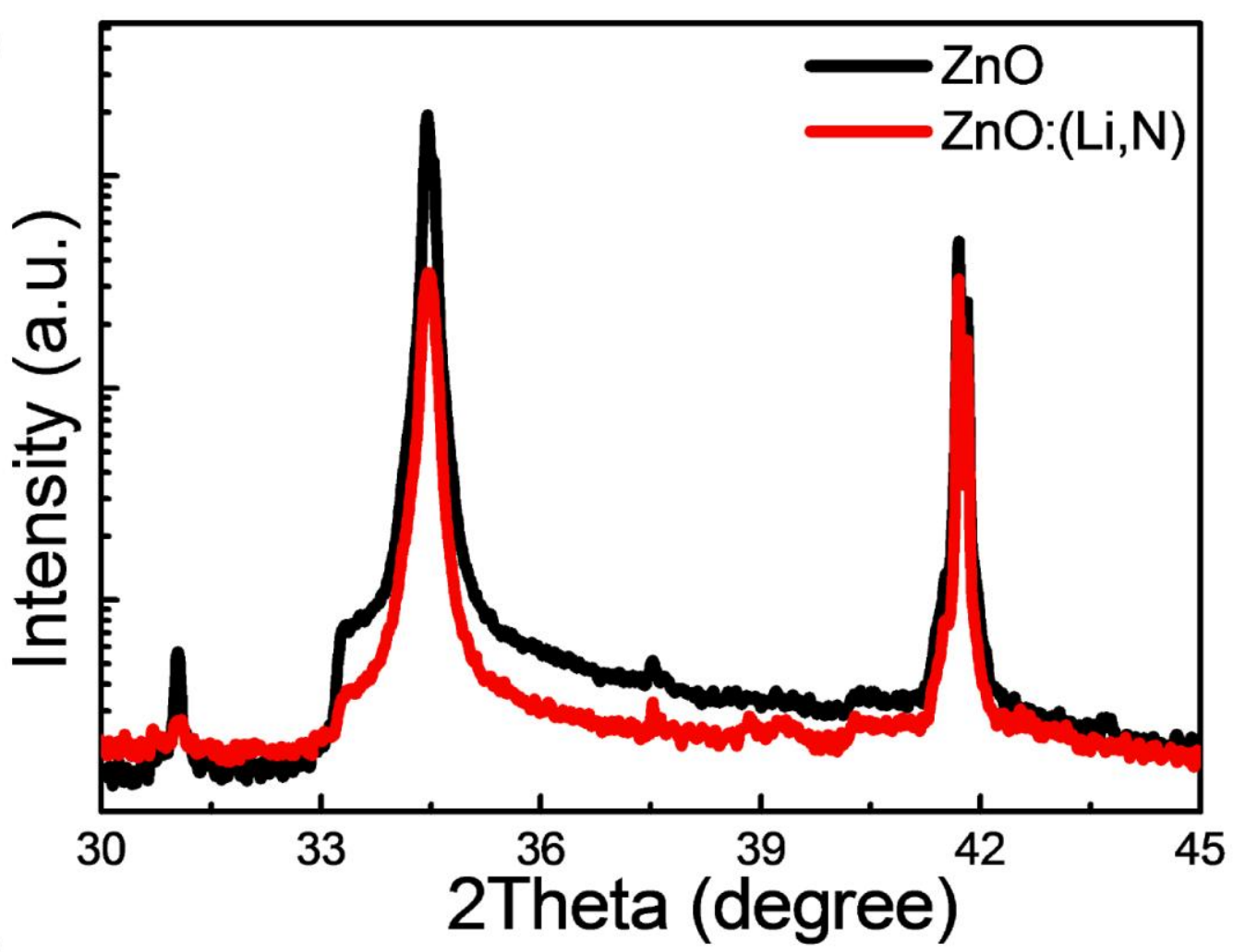

(b)

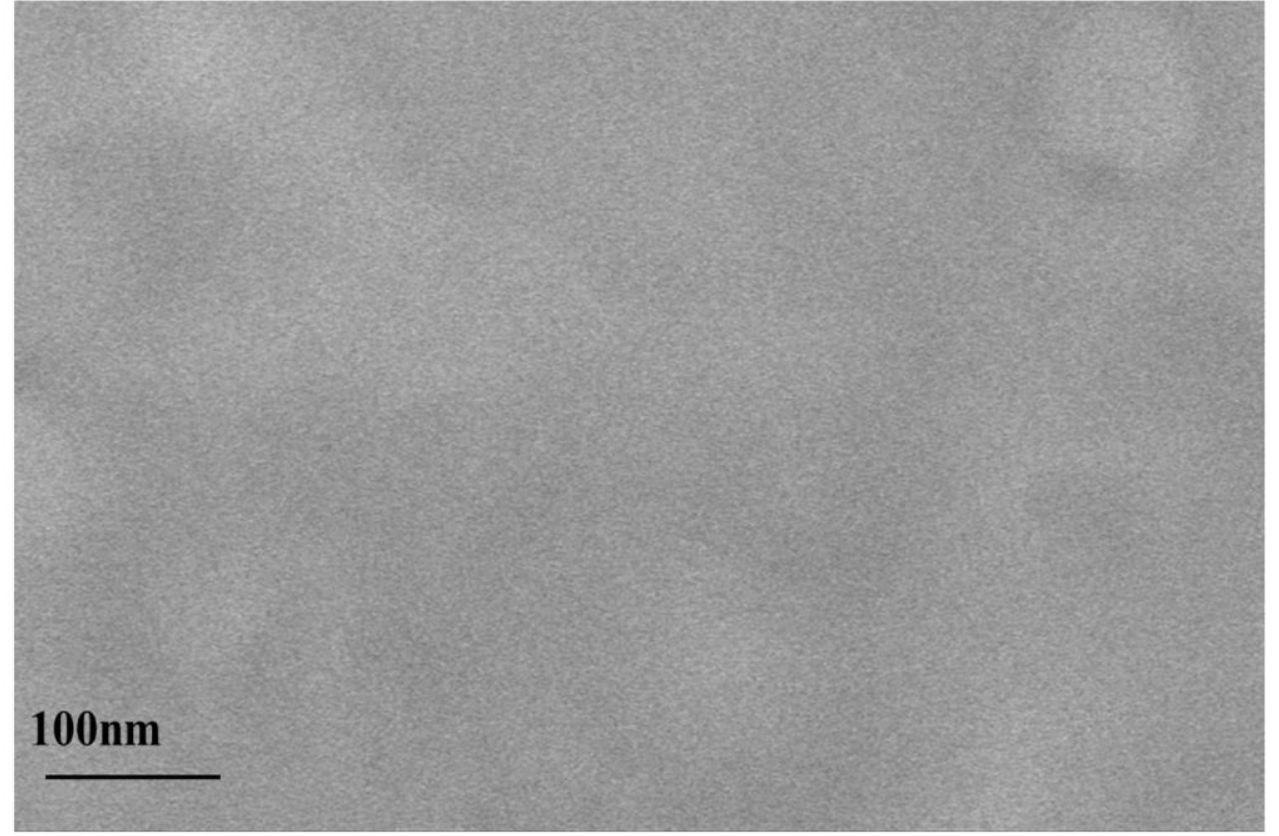



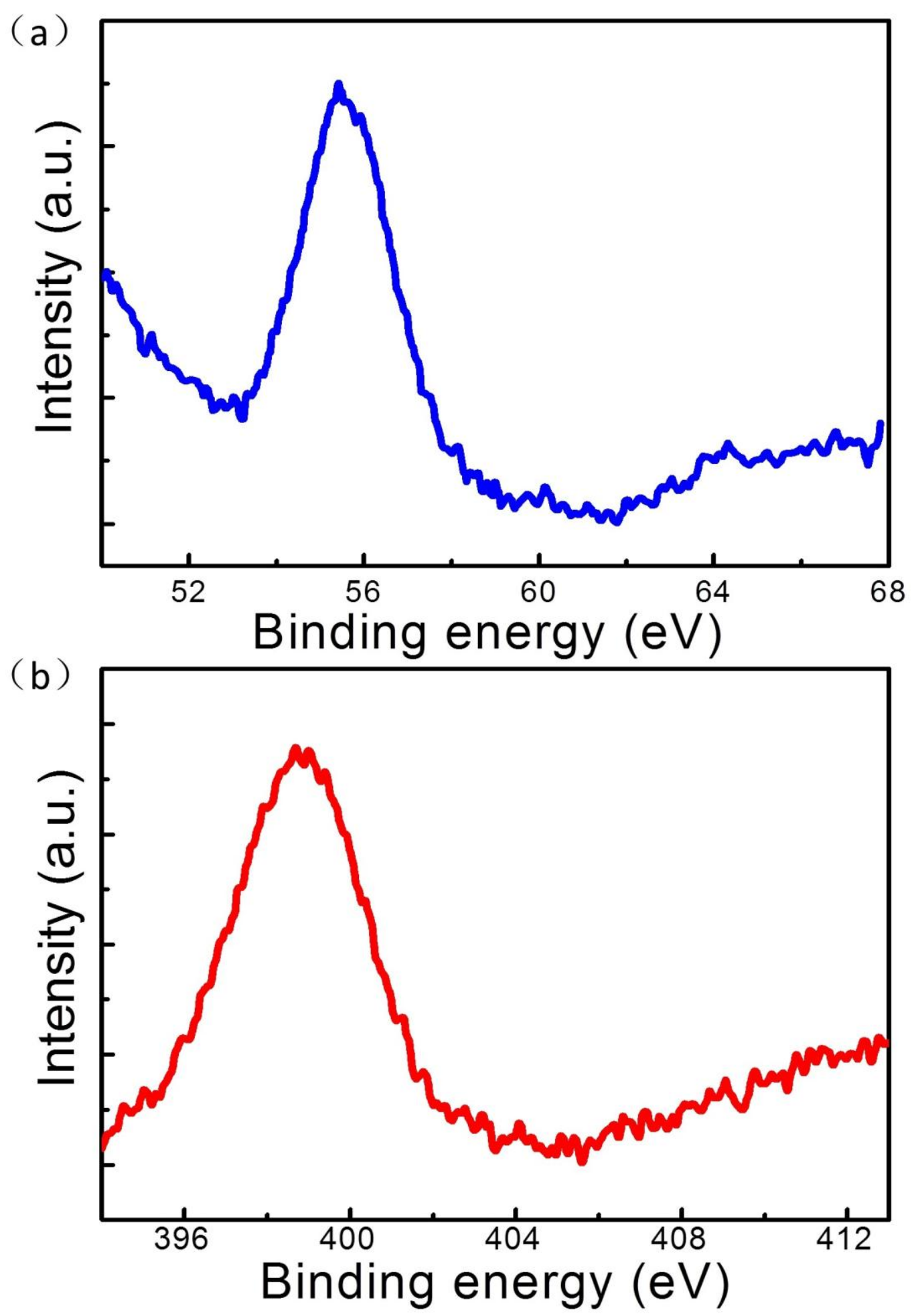
(a)

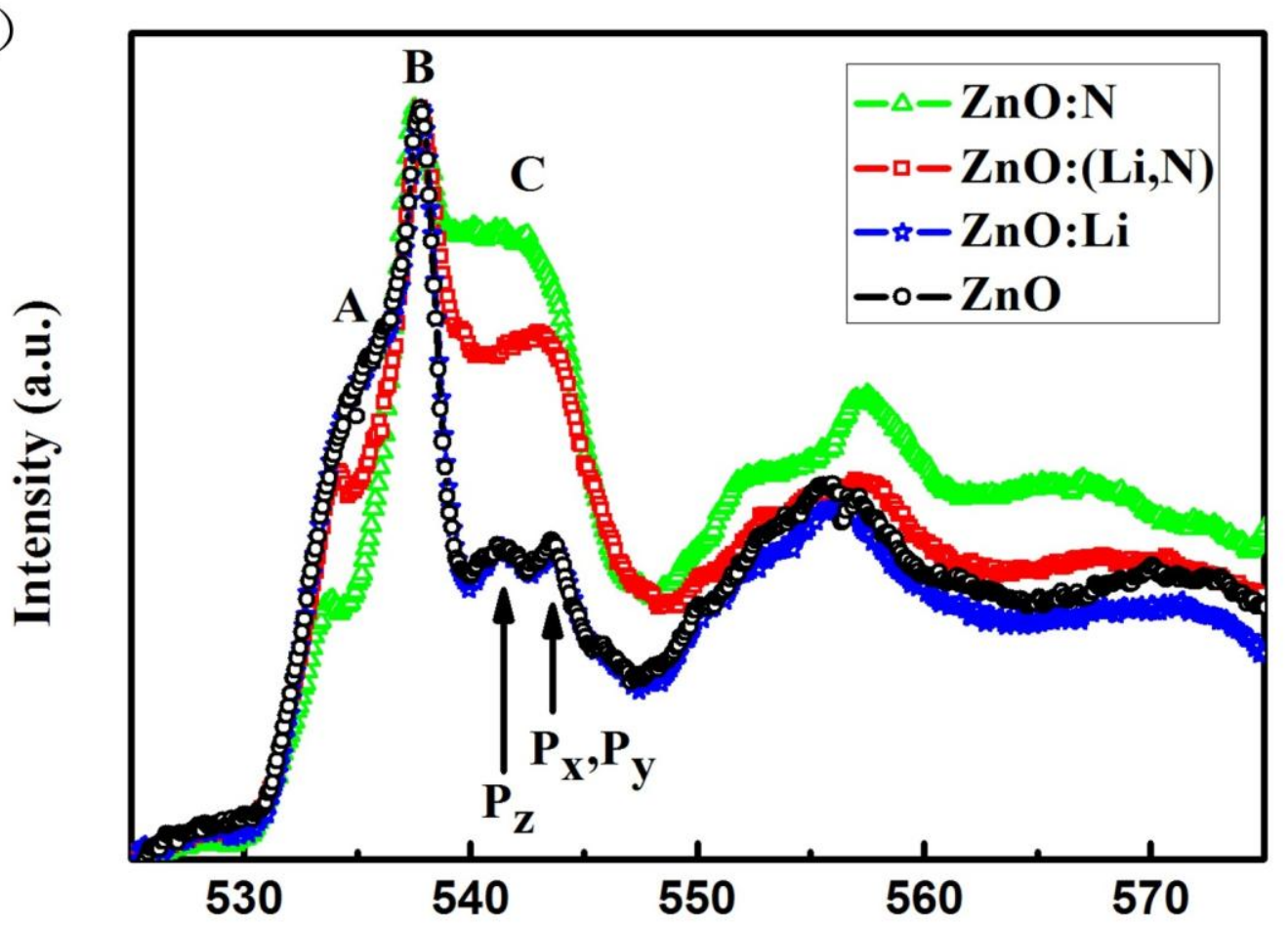

(b)

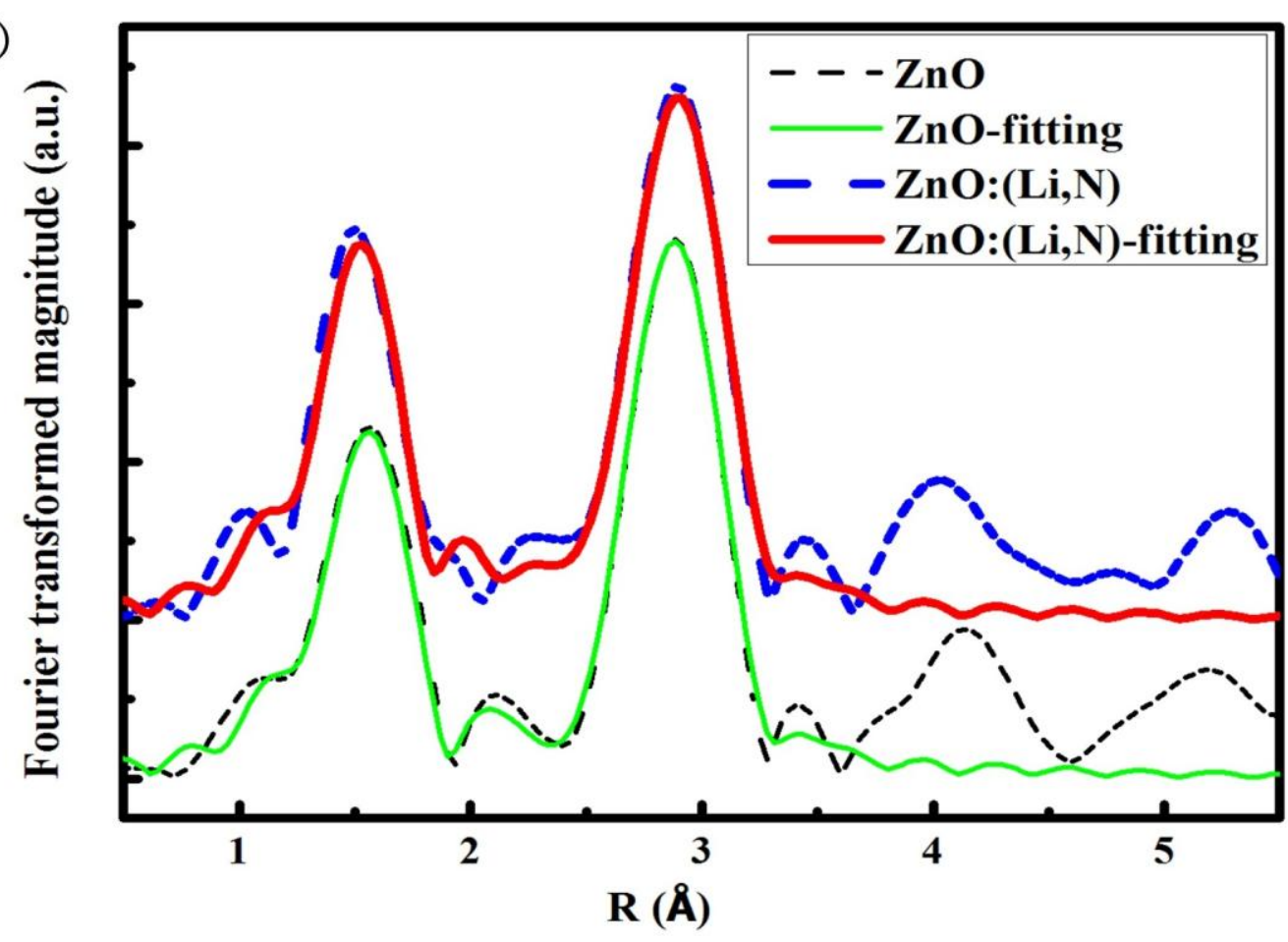


(a)

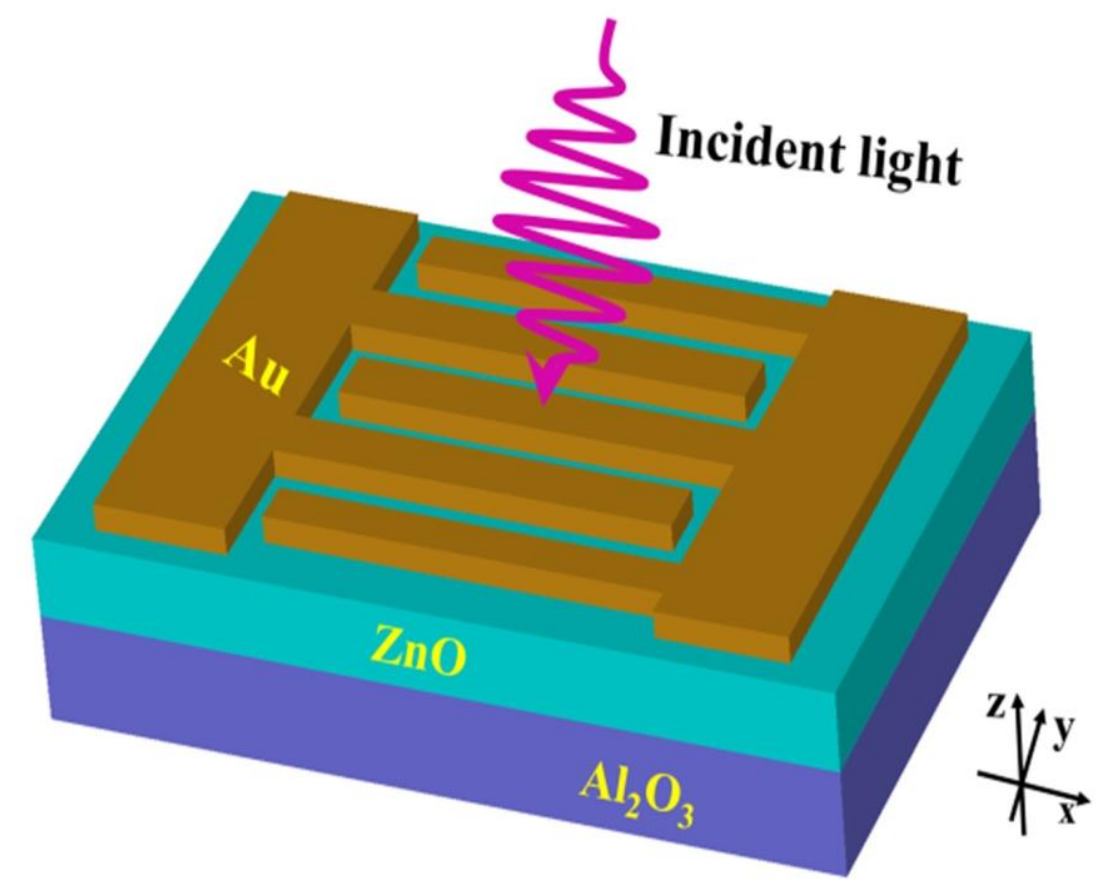

(b)

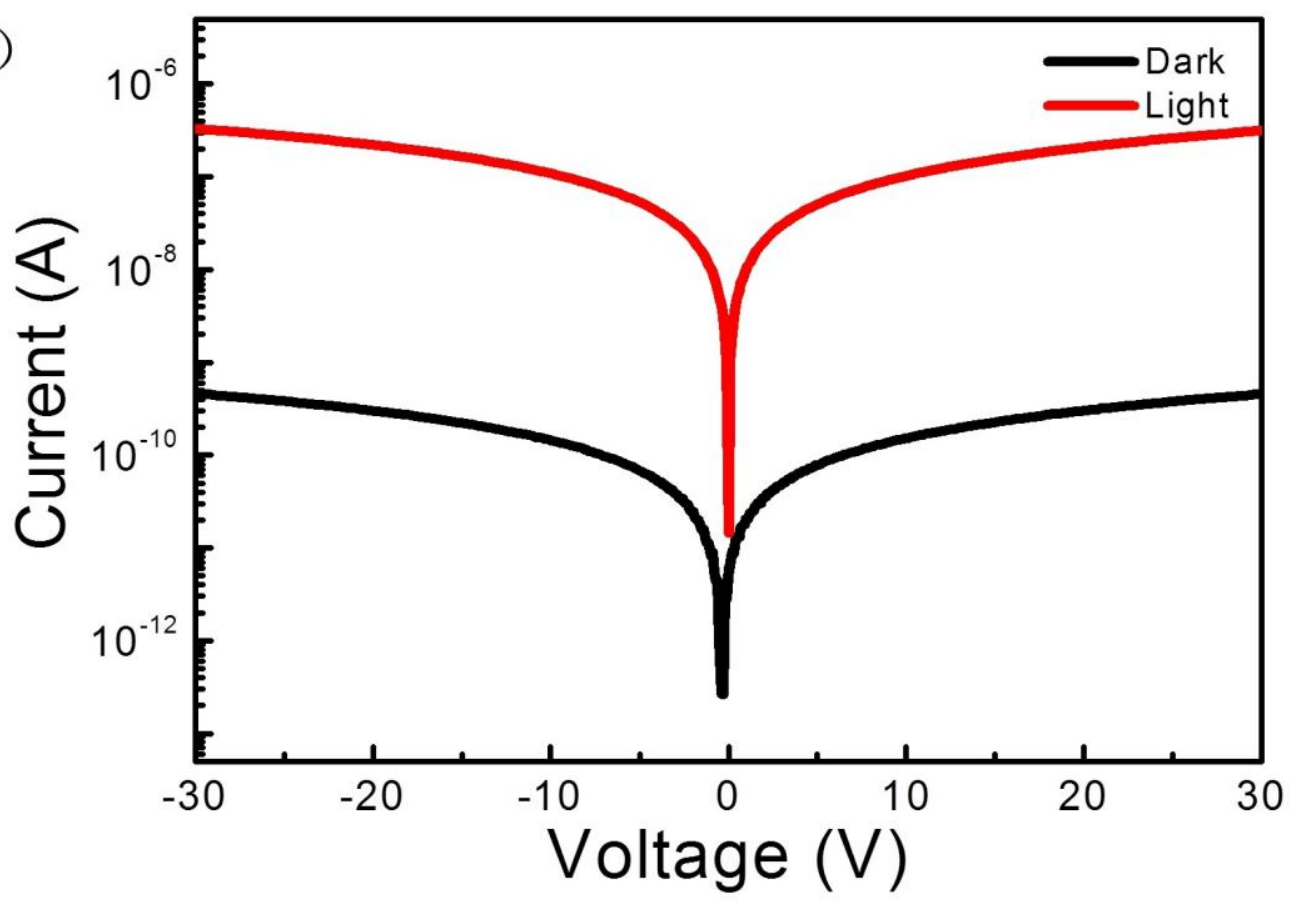




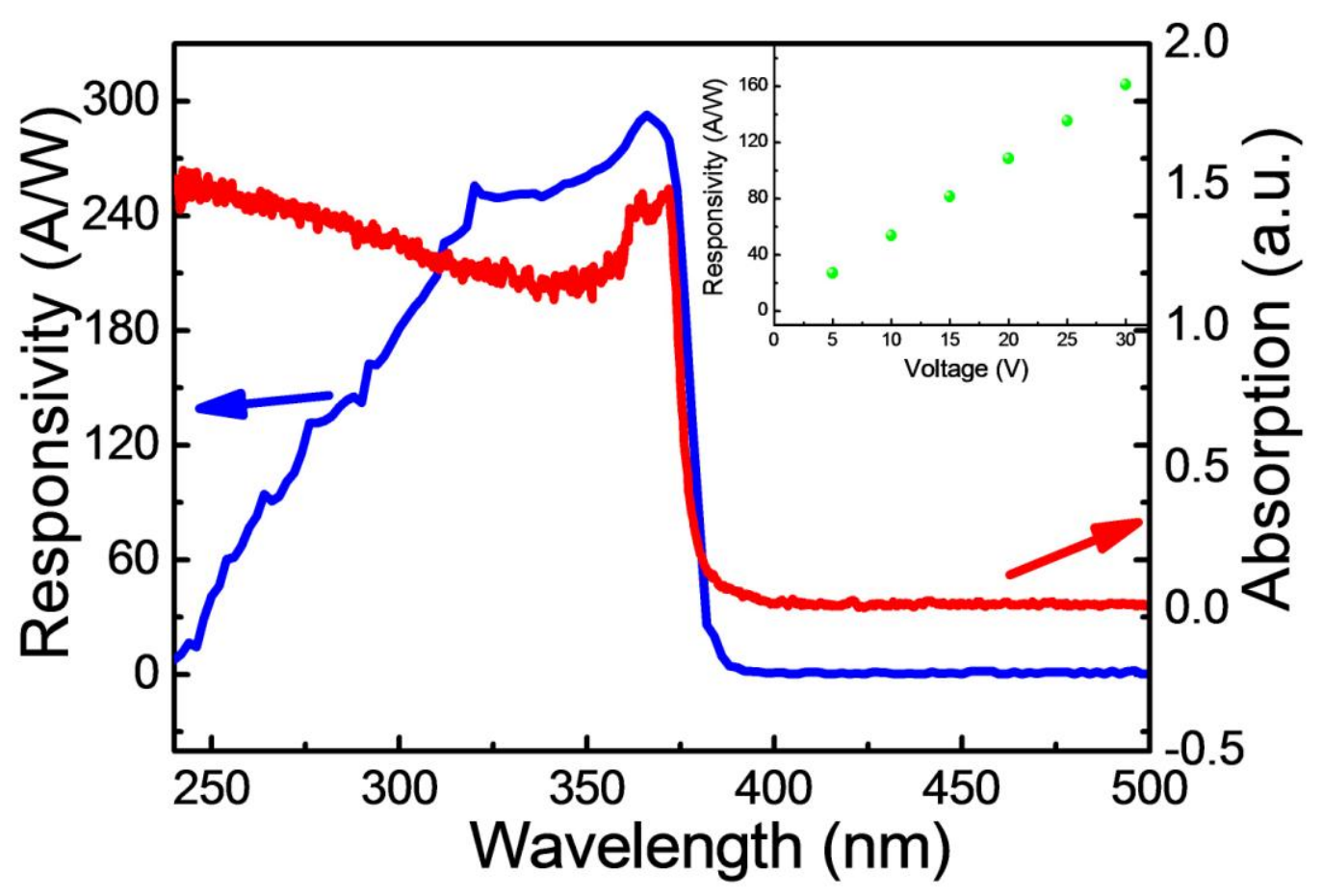


(a)

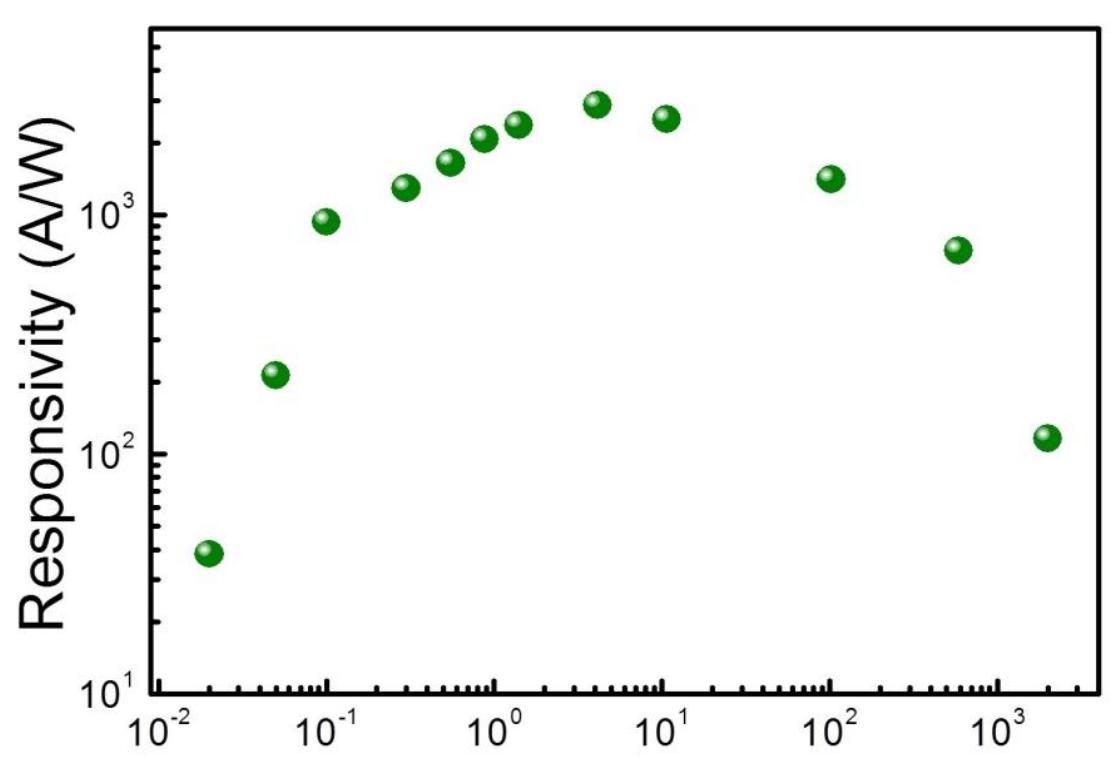

(b)

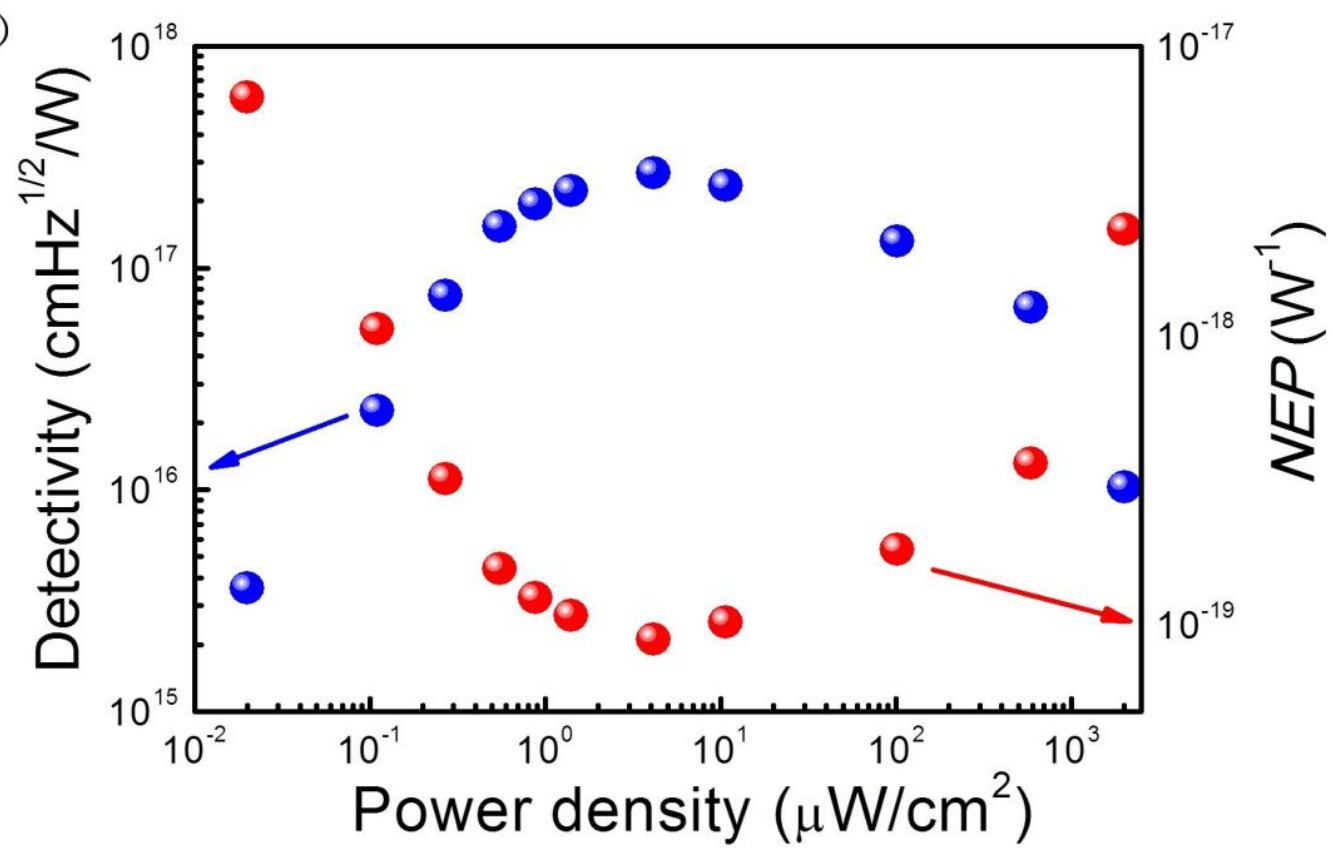

